\title{
Lentinulactam, a hirsutane sesquiterpene with an unprecedented lactam modification
}

\author{
Soleiman E. Helaly ${ }^{\mathrm{a}, \mathrm{b}} \|$, Christian Richter ${ }^{\mathrm{a} \|}$, Benjarong Thongbai ${ }^{\mathrm{c}}$, Kevin D. Hyde $^{\mathrm{c}}$, and Marc Stadler ${ }^{\mathrm{a}} *$ \\ ${ }^{a}$ Department of Microbial Drugs, Helmholtz Centre for Infection Research; and German Centre for Infection Research (DZIF), partner site \\ Hannover/Braunschweig, Inhoffenstrasse 7, 38124 Braunschweig, Germany \\ ${ }^{b}$ Department of Chemistry, Faculty of Science, Aswan University, Aswan 81528, Egypt \\ ${ }^{c}$ Institute of Excellence in Fungal Research, Mae Fah Luang University, Chiang Rai 57100, Thailand \\ $\|^{\text {Authors contributed equally to the manuscript }}$
}

\section{ARTICLE INFO}

Article history:

Received

Received in revised form

Accepted

Available online

\section{Keywords:}

Lentinus

Sesquiterpene

Hirsutane

Mosher ester

Absolute configuration

\section{ABSTRACT}

A novel sesquiterpene featuring an unprecedented modification of the hirsutene scaffold, lentinulactam (1), along with four known metabolites, connatusin A (2), connatusin B (3), 6hydroxy-2,2-dimethylchroman-4-one (4), and 6-methoxy-2,2-dimethylchroman-4-ol (5) were obtained from the cultures of the basidiomycete fungus Lentinus cf. fasciatus. The absolute configuration of compound $\mathbf{1}$ was determined on the basis of the NMR spectroscopic data and Mosher ester analysis. The isolation, structure elucidation, and biological evaluation are reported. Lentinulactam (1) is the first hirsutane terpenoid containing an unusual bridged lactam ring with an exocyclic double bond. Moreover, compound (1) represents the first member of hirsutane family having the opposite absolute configuration to those determined for other hirsutanes.

2016 Elsevier Ltd. All rights reserved. 
Basidiomycetes are a rich source for structurally diverse sesquiterpenes, ${ }^{1,2}$ with the linear triquinanes as a prominent compound class of more than 80 reported examples discovered since $1947 .{ }^{3}$ Hirsutanes $^{4}$ and capnellenes ${ }^{5}$ are the most common scaffolds of the triquinanes. A series of hirsutane sesquiterpenoids were previously isolated from fungi. As exemplified by phellodonic acid from Phellodon melaleucus, many of them possess antibacterial and antifungal activites. ${ }^{6}$ Moreover, the chondrosterins and hirsutanols showed cytotoxicity, $^{7}$ connatusins and dihydrohypnophilin showed antimalarial and cytotoxic activities, ${ }^{8}$ whereas coriolin C, xeromphalinones and pleurocybellone also have cytotoxic activities. ${ }^{3}$ Several triquinane sesquiterpenes with modifications of the hirsutane scaffold were reported. The modifications are manifested in oxygenation, unsaturation, degradation or rearrangement to form different ring skeletons. In our efforts to discover new natural products from Thai Basidiomycota, ${ }^{9}$ we report in this paper on the isolation, structure determination and the biological evaluation of novel hirsutane compounds with unprecedented modification named lentinulactam (1), along with four known compounds, connatusin A (2), ${ }^{8}$ connatusin B (3), ${ }^{8} 6-$ hydroxy-2,2-dimethylchroman-4-one (4), ${ }^{10}$ and 6-methoxy-2,2dimethylchroman-4-ol (5) ${ }^{11}$ from the basidiomycete Lentinus $\mathrm{cf}$. fasciatus collected in Thailand. The structure of the new compound was determined on the basis of spectral data. The absolute configuration was determined on the basis of NMR data and Mosher ester analysis (MTPA). The known compounds were

identified by comparison of the NMR data with those previously reported. Furthermore, the morphological description and molecular identification of the producing organism is illustrated and discussed.

Lentinulactam (1) was obtained as a white amorphous powder and was determined to have the molecular formula of $\mathrm{C}_{15} \mathrm{H}_{23} \mathrm{O}_{3} \mathrm{~N}$ on the basis of HRESIMS data at $m / z 266.1753[\mathrm{M}+\mathrm{H}]^{+}$(calcd 266.1751) with 5 degrees of unsaturation. The ${ }^{1} \mathrm{H}$ NMR and ${ }^{13} \mathrm{C}$ NMR data (Table S2) showed two signals at $\delta_{\mathrm{H}} 5.59$ and $6.31\left(\delta_{\mathrm{C}}\right.$ 122.2 ) assigned to an exocyclic methylene group. Together with the carbonyl carbon at $\delta_{\mathrm{C}} 167.8$ were accounted for two unsaturation degrees which revealed that $\mathbf{1}$ has a tricyclic skeleton. The planar structure of lentinulactam was established by comprehensive analysis of the 2D NMR data, particularly from COSY and HMBC experiments (Figure 2). COSY correlations between $\mathrm{H}-1 / \mathrm{H}-2$ and $\mathrm{H} 7-/ \mathrm{H}-8 / \mathrm{H}-6$ together with HMBC correlations network from $\mathrm{H}-1$ to $\mathrm{C}-2 / \mathrm{C}-3, \mathrm{H}-2$ to $\mathrm{C}-3 / \mathrm{C}-$ 6, H-4 to C-2/C-3/C-5/C-6, H-6 to C-5/C-2, H-7 to C-1/C-9, H-8 to $\mathrm{C}-1 / \mathrm{C}-2 / \mathrm{C}-7 / \mathrm{C}-9$ and from the germinal methyls $(\mathrm{H}-10 / \mathrm{H}-11)$ to $\mathrm{C}-1 / \mathrm{C}-9 / \mathrm{C}-8$ revealed the presence of a 5-6 bicyclic carbon skeleton. Furthermore, the unusual bridged lactam ring (ring C) was assigned by a HMBC correlation from the exocyclic methylene to C-14/C-2. In addition, key HMBC correlations from $\mathrm{H}_{3}-12$ to four carbons $\mathrm{C}-2, \mathrm{C}-3, \mathrm{C}-4$, and to C-13, supported by another correlation from $\mathrm{H}-4$ to $\mathrm{C}-13$ and the chemical shift of the non-protonated carbon $\left(\mathrm{C}-5, \delta_{\mathrm{C}} 81.6\right)$, indicated that ring $\mathrm{C}$ is linked between C-3 and C-5. Nevertheless, we had a doubt about the lactam ring that could be a lactone ring instead and $\mathrm{NH}_{2}$ group attached to $\mathrm{C}-5$ rather than $\mathrm{OH}$. In particular, no significant difference would be observed in the chemical shifts of C-5 and C-14 for both cases. Therefore, we have re-measured the NMR data of 1 using DMSO as solvent (Table S2) which revealed three additional signals in the ${ }^{1} \mathrm{H}$ NMR without corresponding carbon signals in the HSQC. The additional signals were assigned to two $\mathrm{OHs}$ and one NH. Significant HMBC correlations were observed from $1-\mathrm{OH}$ to $\mathrm{C}-9 / \mathrm{C}-1 / \mathrm{C}-2,5-\mathrm{OH}$ to C-5/C-6 and from the $\mathrm{NH}$ to $\mathrm{C}-13$ confirmed the position of lactam ring in compound $\mathbf{1}$ (Figure 1). Thus, compound $\mathbf{1}$ was concluded to possess an unusual lactam modification of the hirsutene scaffold represtel@ing a new /nember of the class of hirsutane sesquiterpenoids, for yhich, we pose the trivial name lentinulactam (1).

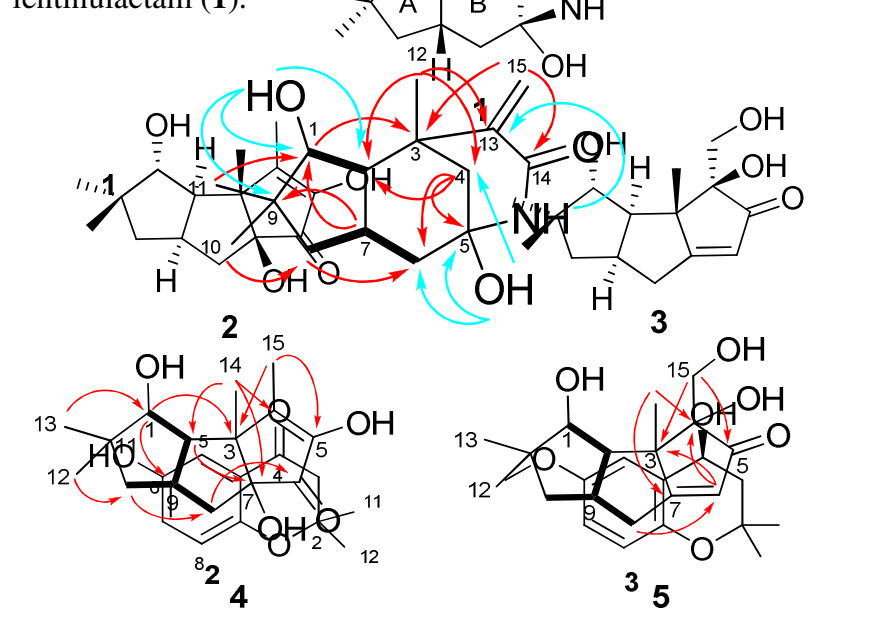

Figure 2. Key HMBC (red arrows, in Methanol-d4), (cyan arrows, in DMSO-d6) and COSY correlations (bold bonds) of lentinulactam (1); Key HMBC and COSY correlations of connatusin A (2) and connatusin B (3)

The relative configuration of lentinulactam (1) was determined on the basis of NOESY data. NOE correlations between $\mathrm{H}-1$ and $\mathrm{H}_{3}-10 / \mathrm{H}-4 \alpha / \mathrm{H}-6 \alpha$ placed these protons on the same face of rings $\mathrm{A}$ and $\mathrm{B}$. In addition, the large coupling constant of $\mathrm{H}-1(11.5 \mathrm{~Hz})$ and the NOE correlations between $\mathrm{H}-2$ and $\mathrm{H}_{3}-11 ; \mathrm{H}-7$ and $\mathrm{H}-2 / \mathrm{H}-8 \beta ; \mathrm{H}-8 \beta$ and $\mathrm{H}_{3}-11 / \mathrm{H}-7$ indicated a trans relationship of $\mathrm{H}-1$ to $\mathrm{H}-2, \mathrm{H}-7$ and $\mathrm{H}_{3}-11$ (Figure 3a). Furthermore, NOE correlation from the exocyclic double bond $\mathrm{H}_{2}-15$ to $\mathrm{H}-2$ revealed that the lactam ring (ring C) is oriented to the same side of $\mathrm{H}-2 / \mathrm{H}-7$. A model calculated for lentinulactam (1) with the mm+ method, a semiempirical method to calculate 3D models of molecular structures, using HyperChem (Ver. 8.0.10) showed the minimized energy $3 \mathrm{D}$ structure indicated a cis-junction of rings $\mathrm{A}$ and $\mathrm{B}$ and a cis relationship between $\mathrm{H}_{3^{-}}$ 12 and 5-OH and thus the angular methyl group $\mathrm{H}_{3}-12$ was cis to $\mathrm{H}-1$ and trans to $\mathrm{H}-2$ (Figure 3a). To determine the absolute configuration of lentinulactam (1) Mosher ester analysis was performed using $\alpha$-methoxy- $\alpha$-trifluoromethylphenylacetic acid (MTPA). Because of low availability of the compound the reaction was carried out with the MTPA acid chlorides in deuterated pyridine and ${ }^{1} \mathrm{H}$ NMR spectrum was measured 
without purification. Despite the poor spectrum quality we could assign all the signal of the MTPA-ester supported by TOCSY spectrum. The methyl groups $\mathrm{H}_{3}-10$ and $\mathrm{H}_{3}-11$ were shifted upfield with $\Delta \delta^{\mathrm{SR}}$ of +0.11 and +0.05 while the protons of $\mathrm{H}-2$ and $\mathrm{H}_{3}-12$ showed downfield shift with $\Delta \delta^{\mathrm{SR}}$ of -0.01 and 0.02 , respectively. This is in accordance with $S$-configuration at C-1. Nevertheless, the assigned configuration was the opposite of those determined for related hirsutane compounds, such as connatusins A and B. Although only the relative configuration was reported, ${ }^{8}$ total synthesis studies conducted later for both connatusins and claimed the confirmation of the absolute configuration $(R$ at $C-1) .^{12,13}$ In this context, we have repeated Mosher ester analysis using a different protocol. ${ }^{14}$ Also we prepared Mosher esters of connatusin A (2) for comparison (described below). The spectra of MTPA-esters were more obvious than those from the first analysis (See supporting information). Clearly, the $\Delta \delta^{\mathrm{SR}}$ values for MTPA esters revealed upfield shifts for the methyls $\mathrm{H}_{3}-11$ and $\mathrm{H}_{3}-10$ with $\Delta \delta^{\mathrm{SR}}$ values of +0.13 and +0.02 , respectively. On the other hand, $\mathrm{H}-2, \mathrm{H}_{3}-12$ and $\mathrm{H}_{2}-15$ revealed negative $\Delta \delta^{\mathrm{SR}}$ values $-0.04,-0.01$ and -0.03 , respectively. Consequently, the absolute configuration at $\mathrm{C}-1$ was unequivocally assigned as $S$-configuration (Figure $3 b$ ).

Thus, the absolute configuration of lentinulactam (1) was assigned to be $1 S, 2 S, 3 S, 5 R, 7 S$. Interestingly, lentinulactam (1) is the first hirsutane sesquiterpene having the opposite absolute configuration to those determined for other hirsutanes.

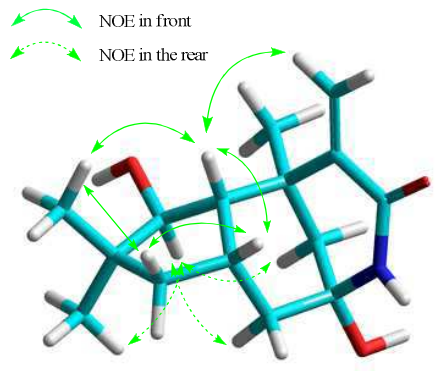

A

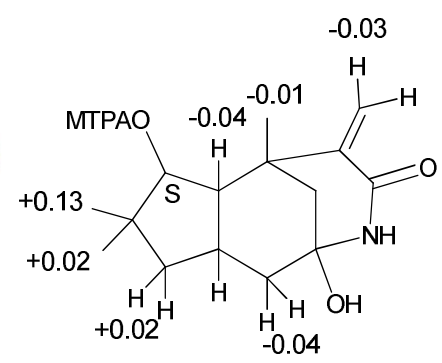

B
Figure 3. A: Calculated 3D Model of lentinulactam (1) using HyperChem, mm+ method; selected NOE correlations are indicated by arrows; B: $\Delta \delta^{\mathrm{SR}}$ values for MTPA esters of lentinulactam (1)

The molecular formula of connatusin A (2) was determined to be $\mathrm{C}_{15} \mathrm{H}_{22} \mathrm{O}_{4}$ by the HRESIMS which showed ion peak at $\mathrm{m} / \mathrm{z}$ 267.1591 $[\mathrm{M}+\mathrm{H}]^{+}$(calcd 267.1591). The ${ }^{1} \mathrm{H}$ NMR and ${ }^{13} \mathrm{C}$ NMR of 2 were similar to those of compound 1, except the lack of the signals of the methylene group $\mathrm{H}_{2}-4$ and the exocyclic methylene $\mathrm{H}_{2}$-13. Additional signals for methyl group $\left(\mathrm{H}_{3}-15\right)$ and $\mathrm{sp} 2$ quaternary carbon at $\delta_{\mathrm{C}} 148.3$ were observed. Furthermore, downfield shift of the carbonyl carbon in 1 from $\delta_{\mathrm{C}} 167.8$ to $\delta_{\mathrm{C}}$ 204.5 together with lack of the nitrogen atom implied by the molecular formula revealed that compound 2 lacks the lactam ring in compare to compound $\mathbf{1}$. Comprehensive analysis of the 2D NMR including COSY, HSQC and HMBC data of 2 (Figure 2) established as connatusin A. ${ }^{8}$ NOESY data were used to determine the relative configuration of compound 2 . NOE correlations between $\mathrm{H}-1$ and $\mathrm{H}_{3}-12 / \mathrm{H}_{3}-14 / \mathrm{H}-8 \mathrm{a}$ showed that these protons are on one side of the 5-5-5 rings system. In addition, the NOE correlations between $\mathrm{H}-2$ and $\mathrm{H}-9 / \mathrm{H}_{3}-13$ indicated a trans relationship of $\mathrm{H}-1$ to $\mathrm{H}-2, \mathrm{H}-9$, The coupling constant of $8.8 \mathrm{~Hz}$ between $\mathrm{H}-2$ and $\mathrm{H}-9$ confirmed the cisjunction between rings A and B. Thus, $\mathrm{H}-2$ and $\mathrm{H}-9$ were located on the opposite side of the 5-5-5 ring system. In conclusion, the relative configuration of compound 2 was consistent with that reported for connatusin A. ${ }^{8}$ Mosher esters were prepared from connatusin A (2) using the previously mentioned protocol, ${ }^{14}$ in order to determine the absolute configuration and for comparison with lentinulactam (1). Analysis of the NMR data of MTPAesters of connatusin A (2) revealed $\Delta \delta^{\mathrm{SR}}$ values of $-0.06,-0.01$ and -0.07 for the methyls $\mathrm{H}-13, \mathrm{H}-12$ and $\mathrm{H}-9$, respectively. In addition, positive $\Delta \delta^{\mathrm{SR}}$ values were observed for the methyls $\mathrm{H}$ 14 and $\mathrm{H}-15$ ( +0.03 and +0.07 , respectively). Therefore, the absolute configuration at $\mathrm{C}-1$ was assigned as $R$-configuration and thus the absolute configuration of connatusin A (2) is $1 R, 2 R, 3 R, 7 S, 9 R$ which is consistent with that previously reported for connatusin A. ${ }^{12,13}$ Our findings supported the previously reported configuration for connatusins and confirmed that lentinulactam (1) has an opposite absolute configuration.

Connatusin $\mathrm{B}$ (3) shared the same molecular formula with connatusin $\mathrm{A}, \mathrm{C}_{15} \mathrm{H}_{22} \mathrm{O}_{4}$. The ${ }^{1} \mathrm{H}$ NMR and ${ }^{13} \mathrm{C}$ NMR spectra were similar to those of connatusin A (2). Nevertheless, the ${ }^{1} \mathrm{H}$ NMR spectrum of compound 3 lacks the signal of the methyl $\mathrm{H}_{3^{-}}$ 15. Furthermore, three additional signals were observed at $\delta_{\mathrm{H}}$ 5.77, 3.50 and 3.66. They were assigned by HSQC spectrum as olefinic methine $(\mathrm{H}-6)$ and oxygenated methylene $\left(\mathrm{H}_{2}-15\right)$, respectively. Comparison of our $1 \mathrm{D}$ and $2 \mathrm{D}$ NMR data with those of connatusin $\mathrm{B},{ }^{8}$ revealed that compound $\mathbf{3}$ is connatusin B.

Compounds 4 and 5 were assigned as 6-hydroxy-2,2dimethylchroman-4-one (4), and 6-methoxy-2,2dimethylchroman-4-ol (5) (Figure 1) by comparison of their HRESIMS and NMR data with those in the literature. ${ }^{10,11}$ The nomenclature of compound $\mathbf{5}$ was incorrectly published by Rukachaisirikul et al. ${ }^{8}$ as 2,2-dimethyl-3-hydroxy-6-methoxy-4chromanone. The correct nomenclature is 6-methoxy-2,2dimethylchroman-4-ol.

The isolated compounds were tested for their biological activities. Regrettably, none of the tested compound showed strong anti-microbial or cytotoxic activity. Only compounds $\mathbf{3}$ and $\mathbf{4}$ showed weak activity against Candida albicans (33.4 $\mu \mathrm{g} / \mathrm{mL}$ ), compound $\mathbf{5}$ showed a very weak activity against Mucor plumbeus $(66.7 \mu \mathrm{g} / \mathrm{mL})$, and compound 4 very weak activity against Rhodotorula glutinis $(66.7 \mu \mathrm{g} / \mathrm{mL})$ (Table $\mathrm{S} 1)$. In addition the compounds $\mathbf{1}$ to $\mathbf{4}$ were tested in a nematode and a phytotoxic assay, without any observed activity. For details of the experimental procedures see the supporting information. Compounds $\mathbf{2}$ to $\mathbf{5}$ are known from fungi, and were first isolated from Lentinus species and species of the closely related species genus Panus. ${ }^{8,10,11}$ To the best of our knowledge none of the compounds has been isolated from Lentinus fasciatus before. Furthermore, compounds $\mathbf{2 , 3}$ and $\mathbf{5}$ were already tested for their cytotoxic properties ${ }^{8}$ and showed only weak or no activity; our study confirms the analysis (compound $\mathbf{5}$ was not tested due to limited material).

\section{Acknowledgments}

Financial support by the German Academic Exchange Service (DAAD) and the Thai Royal Golden Ph.D. Jubilee-Industry program (RGJ) for a joint TRF-DAAD PPP (2012-2014) academic exchange grant to K.D.H. and M.S., and the RGJ for a personal grant to B.T. (No. Ph.D/0138/2553 in 4.S.MF/53/A.3) is gratefully acknowledged. K.D.H. would like to thank the Thailand Research Fund for a grant (BRG5580009). S.E. Helaly is grateful to the Alexander von Humboldt Foundation for 
funding (Georg Forster postdoctoral fellowship). We gratefully acknowledge the help of Wera Collisi for conducting the cytotoxicity bioassays, Christopher Lambert for the molecular lab work and Christel Kakoschke, Cäcilia Schwager for recording NMR and HPLC-MS data.

\section{Supplementary Material}

Taxonomic characterization, NMR spectroscopic data, biological activities, experimental section and spectral data can be found, in the online version, at

\section{References}

(1) De Silva, D. D.; Rapior, S.; Sudarman, E.; Stadler, M.; Xu, J.; Aisyah Alias, S.; Hyde, K. D. Fungal Divers. 2013, 62, 1-40.

(2) Thongbai, B.; Rapior, S.; Hyde, K. D.; Wittstein, K.; Stadler, M. Mycol. Prog. 2015, 14 (10), 1-23.

(3) Liermann, J. C.; Schüffler, A.; Wollinsky, B.; Birnbacher, J.; Kolshorn, H.; Anke, T.; Opatz, T. J. Org. Chem. 2010, 75, 29552961.

(4) Heatley, N. G.; Jennings, M. A.; Florey, H. W. Br. J. Exp. Pathol. 1947, 28 (1), 35.

(5) Kaisin, M.; Sheikh, Y. M.; Durham, L. J.; Djerassi, C.; Tursch, B.; Daloze, D.; Braekman, J. C.; Losman, D.; Karlsson, R. Tetrahedron Lett. 1974, 26, 2239-2242.

(6) Stadler, M.; Anke, T.; Dasenbrock, J.; Steglich, W. Zeitschrift fur Naturforsch. - Sect. C J. Biosci. 1993, 48 (7-8), 545-549.

(7) Li, H.-J.; Jiang, W.-H.; Liang, W.-L.; Huang, J.-X.; Mo, Y.-F.; Ding, Y.-Q.; Lam, C.-K.; Qian, X.-J.; Zhu, X.-F.; Lan, W.-J. Mar. Drugs 2014, 12, 167-175.

(8) Rukachaisirikul, V.; Tansakul, C.; Saithong, S.; Pakawatchai, C.; Isaka, M.; Suvannakad, R. J. Nat. Prod. 2005, 68, 1674-1676.

(9) Richter, C.; Helaly, S. E.; Thongbai, B.; Hyde, K. D.; Stadler, M. J. Nat. Prod. 2016, 79 (6), 1684-1688.

(10) Kis, Z.; Closse, A.; Sigg, H. P.; Hruban, L.; Snatzke, G. Helv. Chim. Acta 1970, 53 (7), 1577-1597.

(11) Abraham, W.-R.; Abateb, D. Zeitschrift für Naturforsch. C 1995, 50 (11-12), 748-750.

(12) Bon, D. J.-Y. D.; Banwell, M. G.; Cade, I. A.; Willis, A. C. Tetrahedron 2011, 67, 8348-8352.

(13) Bon, D. J. Y. D.; Banwell, M. G.; Willis, A. C. Tetrahedron 2010, 66, 7807-7814.

(14) Hoye, T. R.; Jeffrey, C. S.; Shao, F. Nat. Protoc. 2007, 2 (10), $2451-2458$. 